\title{
Biology Schemata Knowledge Organization and Meaning Formation Due to Learning: A Constructive-Chronometric Approach to Concept Mapping Usability
}

\author{
Maria Elena Urdiales-Ibarra, Ernesto Octavio Lopez-Ramirez, Claudia Castro-Campos, \\ Maria Guadalupe Villarreal-Treviño, Janay Emmanuel Carrillo-Colon \\ Cognitive Science Laboratory, Department of Psychology, Universidad Autonoma de Nuevo Leon, Monterrey, Mexico \\ Email: malena_urdiales@hotmail.com
}

How to cite this paper: Urdiales-Ibarra, M. E., Lopez-Ramirez, E. O., Castro-Campos, C., Villarreal-Treviño, M. G., \& Carrillo-Colon, J. E. (2018). Biology Schemata Knowledge Organization and Meaning Formation Due to Learning: A Constructive-Chronometric Approach to Concept Mapping Usability. Creative Education, 9, 2693-2706

https://doi.org/10.4236/ce.2018.916203

Received: October 30, 2018

Accepted: December 7, 2018

Published: December 10, 2018

Copyright ( $) 2018$ by authors and Scientific Research Publishing Inc. This work is licensed under the Creative Commons Attribution International License (CC BY 4.0).

http://creativecommons.org/licenses/by/4.0/

\begin{abstract}
This study investigated how using concept maps affects meaning formation and schemata organization of a biology course content. Here, high school students taking an introductory course on biology were required to provide conceptual definitions for ten course-relevant target concepts by using a natural semantic network technique. This allowed us to computer-simulate schemata behavior and select schemata-related concepts that were used to compare these word pairs against other semantic related concepts in a semantic priming study before and after the course. An experimental group used concept maps as a learning tool whereas the control did not. Results showed that semantic priming effects to schemata related concepts are obtained only for students who used concept maps as a learning tool. Implications of the study findings are discussed in the context of a formative learning approach.
\end{abstract}

\section{Keywords}

Learning, Biology, Mental Representation, Meaning Formation, Concept Maps

\section{Introduction}

Concept maps' effectiveness as a visual learning tool for meaningful acquisition of organized knowledge has long been debated. For instance, there is empirical evidence showing that training and individual differences can be serious obstacles for concept map usability (Holley \& Danserau, 1984; Martin, Martin, \& 
Southworth, 2015). In addition, alternative learning techniques seem to outperform concept map techniques learning results (Karpicke \& Blunt, 2011). On the other hand, there is a robust body of empirical research supporting concept map tools' effectiveness (for a review, see McAleese, 1999; Farrand, Hussain, \& Hennessy, 2002; Nesbit \& Adesope, 2006, 2013; Schroeder, Nesbit, Anguiano, \& Adesope, 2017).

Ignoring this hot debate, a broad variety of teachers from different academic fields, researchers, and educational technology developers (e.g., Liu \& Lee, 2013; Wang \& Dwyer, 2006) are using concept maps as a learning tool, claiming that these tools offer additional theoretical and practical advantages. First, these tools subscribe to a view of learning where assessment of what is learned by a student must reveal what a learner knows (formative learning) as opposed to evaluating what students do not know, which is the case in classical assessments and testing (summative learning; Arieli, 2013). Thus, it is assumed that graphically representing acquisition and organization of newly acquired knowledge into a general visual framework/structure empowers students with the conscious and controlled externalization of their knowledge in long-term memory through specific representational formats. A considerable number of concept map models have been developed to analyze different aspects of this student-controlled externalization of acquired knowledge (mental representation analysis), such as semantic networks (Clariana, 2010a, 2010b; Holley \& Danserau, 1984) and comparable tools (concept mapping, tree diagrams, causal diagrams, etc.; Hyerle, 2009).

Second, mental representation analysis approaches are accompanied by cognitive methods and techniques to ensure that conceptual change due to learning has been really integrated into long-term memory. For example, authors of long-term knowledge retention studies argue that students tend to retain a reduced knowledge schema of previously tested knowledge only (e.g., Conway, Cohen, \& Stanhope, 1991, 1992). On the other hand, Morales and colleagues (Gonzales et al., 2013; Morales \& Lopez, 2016) have argued that, by using semantic priming studies (Mcnamara, 2005) it is possible to immediately identify if schemata-related concepts due learning exist in the lexicon after a course has ended (schemata priming effects). This is relevant, since learned concept organization produces long-term priming effects whenever newly acquired semantics-related concepts are integrated in long-term memory (Becker, Moscovitch, Behrman, \& Joordens, 1997).

Taking together the constructive nature of concept mapping during learning (Jonassen, Beisner, \& Yacci, 1993) as well as chronometric assessment of learning, a powerful formative approach for assessing and facilitating learning can be stablished. There is no need to continue comparing the most usable properties of concept mapping (formative learning information) against summative approaches of learning (e.g., achievement indexes).

Here, it is argued that, even when concept mapping has extensively been used to emphasize constructive aspects of knowledge acquisition in biology (e.g., cell 
biology, Allen \& Tammer, 2003; biology research, Wallace, 1990; tertiary biology classes, Bunting, Coll, \& Campbell, 2006; and other subjects, Kinchin, 2015; Lalor \& Rainford, 2014), this academic endeavor remains incomplete, since no constructive/chronometric methodology has been considered to assure long-term retention of new knowledge due to concept mapping effects.

Next, we introduce a study considering a course on biology to put under constructive/chronometric scrutiny the effect of using the concept mapping as a learning tool in this academic field.

\section{Method}

A cognitive constructive-chronometric assessment approach (Morales, Lopez, Castro, Villarreal, \& Gonzales, 2017) was considered to determine the effect of using a concept mapping technique for long-term memory knowledge organization and meaning formation in a biology course.

In a typical constructive-chronometric study, students' mental representations of course content are obtained using a natural semantic network. Here, they are required to define the target concepts that are related by a schema both before and at the end of a course. This technique has been tested and was shown to produce definitions of the represented objects that are based on their meaning, not on free associations or pure semantic category membership (Figueroa, Gonzales, \& Solis, 1975). Furthermore, simulated schemata behavior is implemented by using these conceptual definitions to obtain schemata-related concepts that are used in word recognition studies to determine if students have successfully integrated new knowledge in long-term memory after the course. More details are introduced next.

\subsection{Participants}

The study sample comprised of 167 high school middle class students from the north of Mexico (Monterrey city) belonging to five groups taking an introductory course on biology. The teacher was the same for all groups. He was instructed to be aware of not to bias his instruction motivation due to concept mapping as a learning tool. The control group consisted of 64 students (39 females and 25 males), whereas the remaining 103 participants (61 females and 42 males) formed the experimental group. Their age ranged between 14 and 15 years old. Their age ranged between 19 and 21 years old. These students are representative of middle class high school students at the north of Mexico. No credits or economic remuneration provided for participation.

\subsection{Instruments}

\subsubsection{Concept Mapping}

The concept map (Cmap) used in this study is under the Theory of Meaningful Learning precepts (ToML; Ausubel, Novak, \& Hanesian, 1986) where Cmaps are considered as schematic devices for representing a set of concepts in a meaningful framework of propositions (Daley, Cañas, \& Stark-Schweitzer, 2007). Here, 
the current study hypothesis assumes that a Cmap hierarchical conceptual structure (by using a constructive approach as suggested by Jonassen, Beisner, \& Yacci, 1993; Jonassen, \& Marra, 1994) is best to test long-term meaningful knowledge retention (for a debate on this topic see Dervensteva, Safayeni, 2004; see also the procedure section).

\subsubsection{Mental Representation Analysis Technique}

In order to visualize conceptual change due to learning, a computer software specialized in analysis of meaning formation through natural semantic nets EVCOG was used (Morales \& Lopez, 2016; Morales \& Santos, 2015). The cognitive technique called natural semantic network analysis (e.g., Torres \& Garza, 2014) requires participants to provide single concept definers for target concepts of a course, in this case: SCIENCE, ECOLOGY, BIOCHEMICHALS, THEORY, ENERGY, METHODOLOGY, BIOLOGY, FOOD CHAIN, ENVIRONMENT, and LIVING BEINGS. These concepts were provided by the teacher as central and relevant to a school course regarding the schema of introduction to biology. As a result, a set of lists is obtained, each containing the ten highest pondered definers for the teacher's target concepts. To achieve this, the following values are computed:

$\mathbf{M}$ value: The sum of the ranks is assigned by all participants to each definer concept. This is a relevant measure for each concept as a definition of the target concept.

SAM (Semantic Analysis of $M$ value) group: The 10 highest-ranked definers with the highest $\mathrm{M}$ values for a target concept. This is the set of 10 definers that construct most of the meaning of the target concept in a network.

Some other values, such as the net density ( $G$ value) and richness of definers for each target (J value) are computed. This technique produces definitions (using single concept definers like nouns, adjectives, etc.). Moreover, this technique allows obtaining semantic concept representations from teachers and students, rather than from an idiosyncratic semantic net formed by a researcher or an expert.

Furthermore, a semantic net can be drawn if desired. In this study, the weight association between two concepts (W) is computed by applying the following derivative of the Bayesian formula:

$$
\begin{aligned}
\text { Wij }= & -\ln [\mathrm{p}(\mathrm{X}=0 \& \mathrm{Y}=1) \mathrm{p}(\mathrm{X}=1 \& \mathrm{Y}=0)] \\
& \times[\mathrm{p}(\mathrm{X}=1 \& \mathrm{Y}=1) \mathrm{p}(\mathrm{X}=0 \& \mathrm{Y}=0)]^{1}
\end{aligned}
$$

where $\mathrm{X}$ and $\mathrm{Y}$ represent the pair of concepts to be associated. In determining association values among concepts in a natural semantic network, the joint probability value $\mathrm{p}(\mathrm{X}=1 \& \mathrm{Y}=0)$ can be obtained by computing how many times the definer $\mathrm{X}$ of a pair of concepts appeared in a list of definers in which $\mathrm{Y}$ did not appear, and the same for the other probability values. These association weight values were used as an input matrix to a Constrain Satisfaction Neural Net (CSNN) to simulate schemata behavior in the current study (Rumelhart, 
Smolensky, McClelland, \& Hinton, 1986). Furthermore, a software implementation was developed for visualizing meaning formation through a GEPHI network analysis (GEPHI, 2017). Here, metrics for concept organization like net modality, cluster indexing, concept centrality, etc., can be obtained (Bersano, Schaefer, \& Bustos, 2012).

\section{Procedure}

\subsection{Concept Map Generation}

Three groups of 38 students each were required to use a concept map technique as a learning tool through the course period (six months). Concept maps gathering requirements are shown in Table 1.

Working phase, concept map type to develop, concept map component to emphasize, assessment instrument to evaluate a concept map and kind of assessment.

\subsection{Mental Representation Gathering}

To obtain conceptual definitions to target concepts, participants were seated in front of a computer. The EVCOG system provided them with instructions on how to proceed through the definition task. Then a definition practice trial was presented to define a target concept (either apple or dog). This was followed by the study where target concepts were randomly presented. The maximum time allowed for the production of definers for each target concept was 60 seconds,

Table 1. Concept map use guidelines.

\begin{tabular}{|c|c|c|c|c|c|}
\hline \multicolumn{6}{|c|}{ Phase I } \\
\hline Topic: & Type of map & Instructions & Emphasis & Instrument & Evaluation \\
\hline & & & Type of connectivity & & \\
\hline What is science? & Hierarchical organization & Session class 3 & Principal concepts & Rubric 3 & Co-assessment \\
\hline Science in context & Hierarchical organization & Session class 4 & and propositions & Rubric 4 & Self-evaluation \\
\hline Study of life & Hierarchical organization & Session class 5 & Information hierarchy & Rubric 5 & Hetero-evaluation \\
\hline Integrative activity of Phase I & Hierarchical organization & Session class 7 & $\begin{array}{l}\text { Information containers, } \\
\text { connection lines, propositions } \\
\text { and Information hierarchy }\end{array}$ & Rubric 7 & Hetero-evaluation \\
\hline \multicolumn{6}{|c|}{ Phase II } \\
\hline What is ecology? & Hierarchical organization & Session class 8 & $\begin{array}{l}\text { Information hierarchy } \\
\text { and visual representation }\end{array}$ & Rubric 8 & Co-assessment \\
\hline $\begin{array}{l}\text { Energy producers and } \\
\text { consumers }\end{array}$ & Hierarchical organization & Session class 9 & $\begin{array}{l}\text { Visual representation } \\
\text { and interpretation }\end{array}$ & Rubric 9 & Co-assessment \\
\hline $\begin{array}{l}\text { Energy flow } \\
\text { inside ecosystems }\end{array}$ & Spider & Session class 10 & $\begin{array}{l}\text { Concept map variation } \\
\text { attending connectivity } \\
\text { among concepts }\end{array}$ & Rubric 10 & Hetero-evaluation \\
\hline Matter cycles & Hierarchical organization & Session class 11 & $\begin{array}{l}\text { Information hierarchy, } \\
\text { connectivity, propositions } \\
\text { and Information containers. }\end{array}$ & Rubric 11 & Self-evaluation \\
\hline $\begin{array}{c}\text { Integrative activity } \\
\text { of Phase II }\end{array}$ & Hierarchical organization & Session class 13 & $\begin{array}{l}\text { Information containers, } \\
\text { connection lines, propositions } \\
\text { and Information hierarchy }\end{array}$ & Rubric 13 & Hetero-evaluation \\
\hline
\end{tabular}


while 30 seconds were allowed for the rating of the definers for each concept. Subjects took around 15 minutes to complete this process. At the end of the course, students were required to take a semantic priming to compare their recognition latencies to schemata related concepts against associative related word pairs and non-related word pairs.

\section{Results}

Repeated measures ANOVA was carried on semantically-related word pairs. All participants were included, since each provided $\geq 90 \%$ correct latencies. As expected, the results showed a significant main effect for the group factor, $F(1$, $717)=16.112, p=0.00007, \eta 2 p=0.021978$. Figure 1 shows both groups' word recognition performance in the study.

A significant difference from both groups to recognize semantically related word pairs was obtained $\mathrm{F}(1,717)=3.8504, \mathrm{p}=0.05011$. Furthermore, a post hoc comparison analysis showed that only the experimental group displayed a significant difference $\mathrm{F}(1,717)=3.61, \mathrm{p}=0.050$, to discriminate schemata-related concepts (schemata priming) from other word pairs at the end of the course. Figure 2 shows an interaction graph (group $\times$ semantic relation), revealing recognition latencies for both groups. Only latencies to semantically related words are presented because these were recognized as different to non-related word pairs.

This result implies that students from the control group did not assimilate information in their long-term memory, since no evidence for schemata information being stored in the lexicon was found. In other words, successful students only learned to pass the course (all of them successfully passed the course). Now,

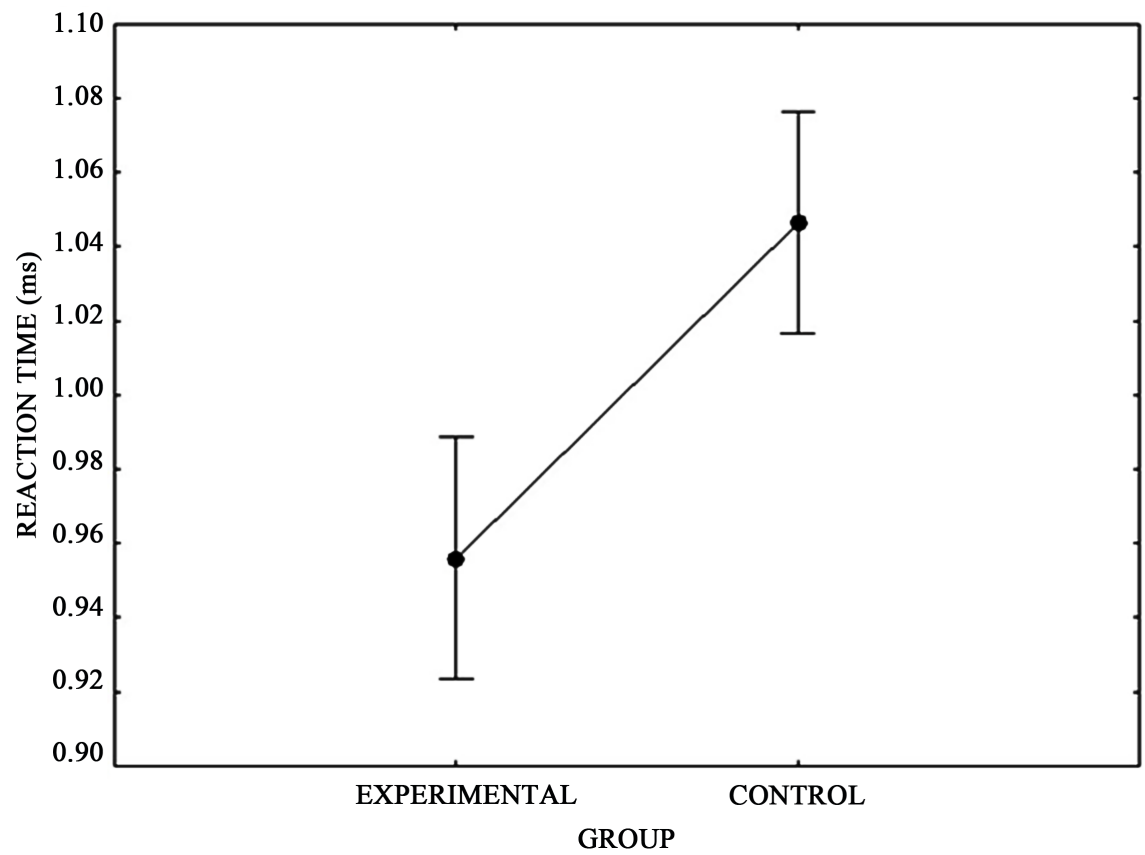

Figure 1. Significant recognition differences between the two groups. 


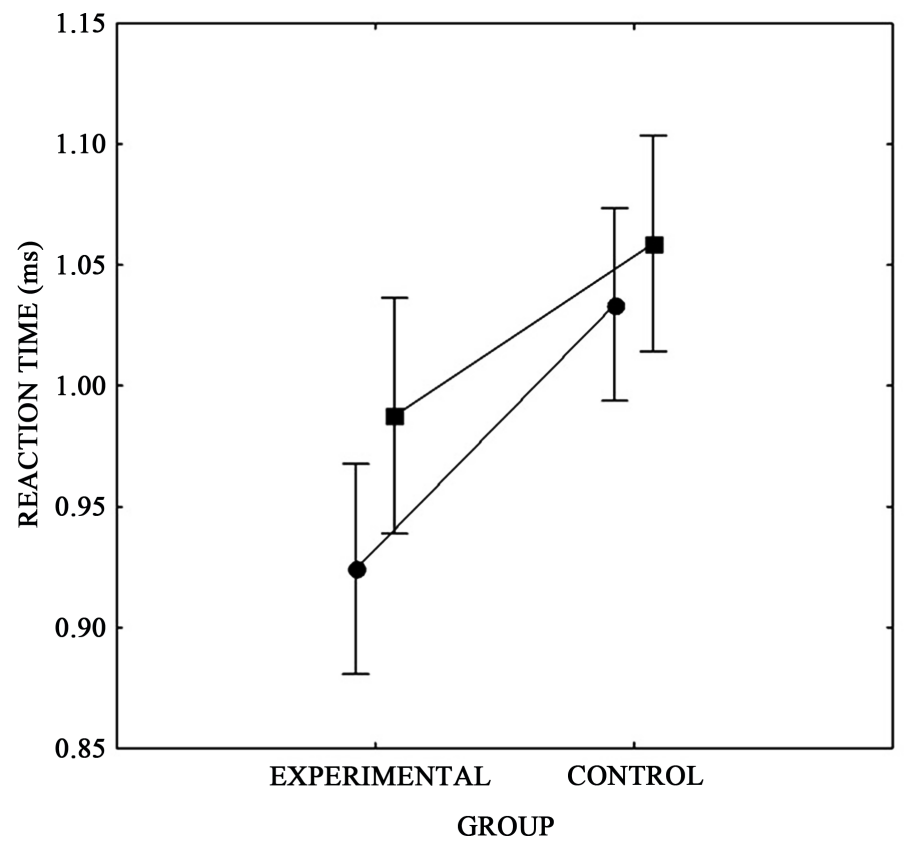

ASSOCIATIVE SCHEMA

Figure 2. Participants' recognition times for semantically related word pairs.

let us identify some conceptual changes due to learning (constructive evaluation) that might relate to this chronometric evaluation (Gonzalez, Lopez, \& Morales, 2013). Figure 3 shows conceptual definitions provided by the experimental group members before the course by using the EVCOG system.

From these conceptual groups (SAM groups), a weight association matrix among concepts can be generated by using Equation (1) presented in the introduction section. The EVCOG system allows the user to automatically generate this matrix and use it to produce visual graphs to conduct GEPHI analysis. Conceptual definitions for the control group are not presented due to space limitation, but GEPHI network graph representations obtained from both groups are presented in Figure 4.

This figure indicates that both groups had some knowledge of biology before starting the course, but some concepts were not integrated in their general knowledge schemas. It is assumed that some meaning underlies these conceptual organizations and the teacher's goal is to impose an improved meaning of course contents through instruction that modifies conceptual change.

Furthermore, Figure 5 shows concept organization of both groups after completing the biology course.

At first glance, Figure 5 reveals that separated concept network organizations were replaced by a unified mental representation (unified meaning).

So, what are the conceptual differences between the beginning and end of the course leading to long-term retention of knowledge in the experimental group? Figure 6 shows conceptual definitions provided by the experimental group members after the course.

It is evident that, after attending the course, the experimental group produced 


\begin{tabular}{|c|c|c|c|}
\hline \multicolumn{4}{|c|}{ TARGET: BIOLOGY } \\
\hline $\begin{array}{c}\text { COMMON } \\
\text { FREQ. } \\
\text { (CF) }\end{array}$ & DEFINERS & $\begin{array}{c}\text { SEMANTIC } \\
\text { VALUE } \\
\text { (M) }\end{array}$ & $\begin{array}{c}\text { INTER } \\
\text { RESPONSE } \\
\text { TIME (IRT) }\end{array}$ \\
\hline 6 & ANIMALS & 445 & 22 \\
\hline 5 & LIFE & 390 & 17 \\
\hline 6 & PLANTS & 317 & 26 \\
\hline 4 & STUDY & 260 & 22 \\
\hline 2 & HUMANS & 181 & 25 \\
\hline 4 & SCIENCE & 180 & 24 \\
\hline 1 & BEINGS & 172 & 24 \\
\hline 2 & MATTER & 126 & 26 \\
\hline 4 & EARTH & 111 & 33 \\
\hline 2 & ECOLOGY & 95 & 32 \\
\hline \multicolumn{4}{|c|}{ J VALUE: 638 } \\
\hline
\end{tabular}

\begin{tabular}{|c|c|c|c|}
\hline \multicolumn{4}{|c|}{ TARGET: SCIENCE } \\
\hline $\begin{array}{c}\text { COMMON } \\
\text { FREQ. } \\
\text { (CF) }\end{array}$ & DEFINERS & $\begin{array}{c}\text { SEMANTIC } \\
\text { VALUE } \\
\text { (M) }\end{array}$ & $\begin{array}{c}\text { INTER } \\
\text { RESPONSE } \\
\text { TIME (IRT) }\end{array}$ \\
\hline 2 & SCIENTIST & 216 & 25 \\
\hline 3 & CHENISTRY & 212 & 28 \\
\hline 4 & MATTER & 197 & 16 \\
\hline 3 & BIOLOGY & 185 & 22 \\
\hline 1 & PHYSICS & 161 & 32 \\
\hline 2 & EXPERIMENT & 157 & 29 \\
\hline 5 & STUDY & 153 & 16 \\
\hline 6 & PLANTS & 107 & 29 \\
\hline 6 & ANIMALS & 105 & 31 \\
\hline 1 & TECHNOLOGY & 98 & 42 \\
\hline \multicolumn{4}{|c}{ J VALUE: 512} \\
\hline \multicolumn{4}{|c|}{ G VALUE: 11.3} \\
\hline
\end{tabular}

BEFORE XXPERIMENTAL GROUP COMMON DEFINERS

Figure 3. Ten highest-valued definers for target concepts (only two groups are presented (left)). Notice that some common definers were obtained (Right). These are used to define several target concepts. The numbers in parentheses specify how many targets considered the definer.
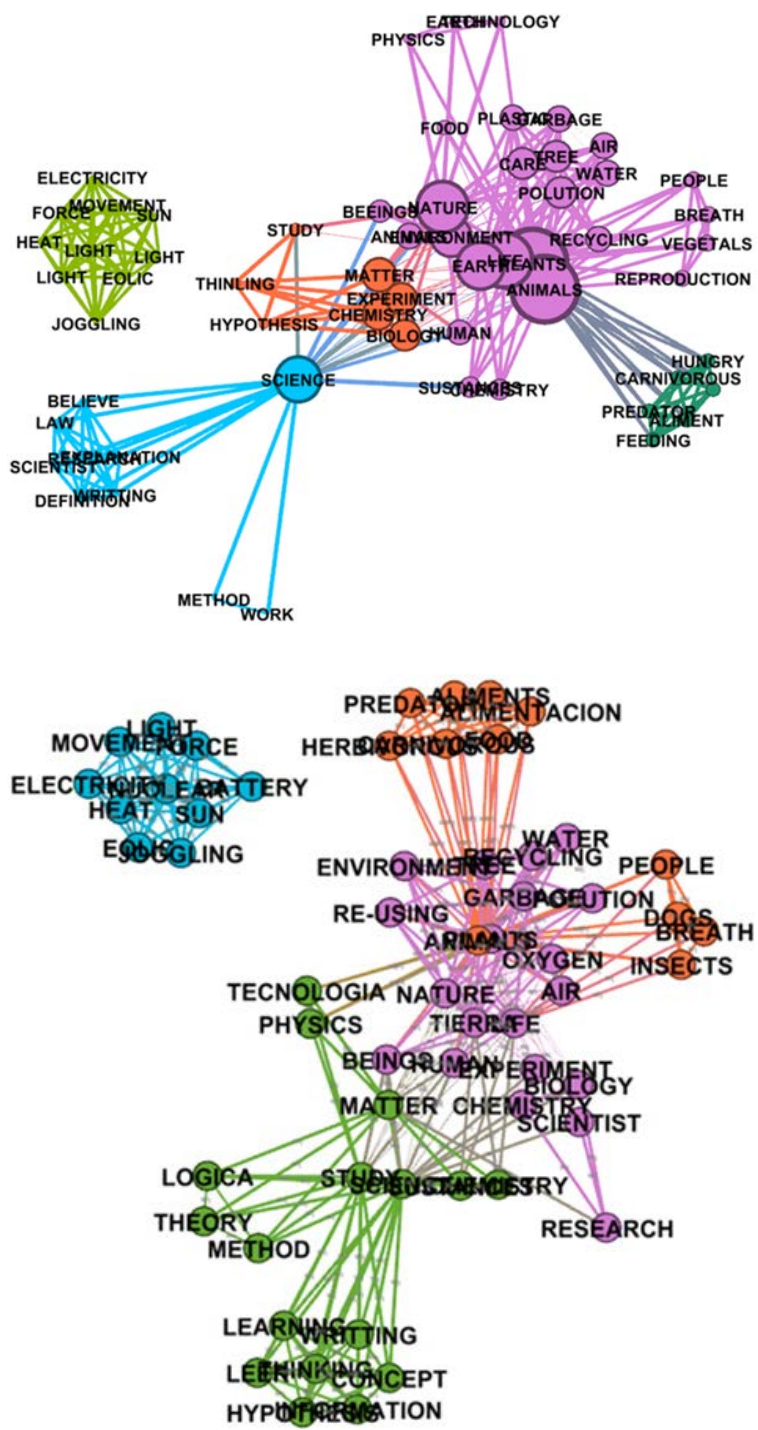

Figure 4. Biology semantic net concept organizations at the beginning of the course for the control group (top) and the experimental group (bottom). 


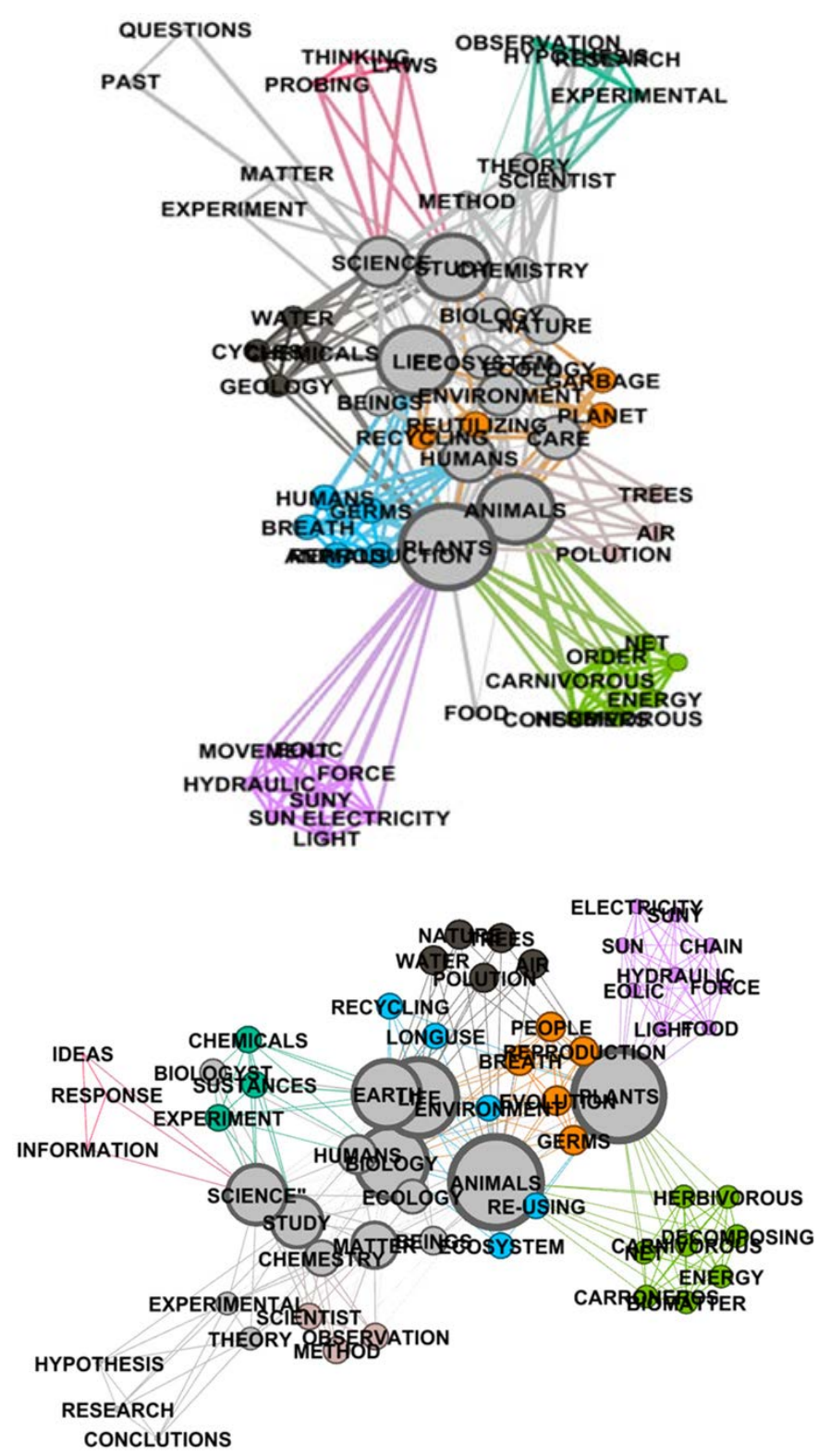

Figure 5. Illustration of semantic conceptual organization due to learning in both groups. Control group is shown on the top, and the experimental group on the bottom.

\begin{tabular}{|c|c|c|c|}
\hline \multicolumn{4}{|c|}{ TARGET: BIOLOGY } \\
\hline $\begin{array}{c}\text { COMMON } \\
\text { FREQ. } \\
\text { (CF) }\end{array}$ & DEFINERS & $\begin{array}{c}\text { SEMANTIC } \\
\text { VALUE } \\
\text { (M) }\end{array}$ & $\begin{array}{c}\text { INTER } \\
\text { RESPONSE } \\
\text { TIME (IRT) }\end{array}$ \\
\hline 6 & ANIMALS & 445 & 22 \\
\hline 5 & LIFE & 390 & 17 \\
\hline 6 & PLANTS & 317 & 26 \\
\hline 4 & STUDY & 260 & 22 \\
\hline 2 & HUMANS & 181 & 25 \\
\hline 4 & SCIENCE & 180 & 24 \\
\hline 1 & BEINGS & 172 & 24 \\
\hline 2 & MATTER & 126 & 26 \\
\hline 4 & EARTH & 111 & 33 \\
\hline 2 & ECOLOGY & 95 & 32 \\
\hline \multicolumn{4}{|c|}{ J VALUE: 638 } \\
\hline \multicolumn{4}{|c|}{ G VALUE: } \\
\hline
\end{tabular}

\begin{tabular}{|c|c|c|c|}
\hline \multicolumn{4}{|c|}{ TARGET: ENVIRONMENT } \\
\hline $\begin{array}{c}\text { COMMON } \\
\text { FREQ. } \\
\text { (CF) }\end{array}$ & DEFINERS & $\begin{array}{c}\text { SEMANTIC } \\
\text { VALIE } \\
\text { (M) }\end{array}$ & $\begin{array}{c}\text { INTER } \\
\text { RESPONE } \\
\text { TIME (IRT) }\end{array}$ \\
\hline 6 & ANIMALS & 492 & 22 \\
\hline 6 & PLANTS & 429 & 17 \\
\hline 1 & TREE & 218 & 22 \\
\hline 1 & AIR & 194 & 31 \\
\hline 2 & ECOLOGY & 186 & 21 \\
\hline 1 & POLUTION & 177 & 26 \\
\hline 1 & WATER & 176 & 29 \\
\hline 1 & NATURE & 149 & 21 \\
\hline 4 & EARTH & 144 & 31 \\
\hline 5 & LIFE & 142 & 32 \\
\hline \multicolumn{4}{|c}{ J VALUE: 636 } \\
\hline \multicolumn{5}{|c|}{ G VALUE: } \\
\hline
\end{tabular}

AFTER Common definers

\begin{tabular}{|c|}
\hline PLANTS - (7) \\
\hline ANIMALS - (5) \\
\hline LIFE - (5) \\
\hline STUDY - (5) \\
\hline SCIENCE - (4) \\
\hline HUMANS - (3) \\
\hline ECOLOGY - (3) \\
\hline ECOSYSTEM (3) \\
\hline NATURE - (2) \\
\hline CHEMISTRY - (2) \\
\hline
\end{tabular}

Figure 6. Conceptual definitions of target concepts due to learning (experimental group). 
a richer set of common definers. Thus, a richer structure underlying concept organization was stablished. The control group also presented a richer set of common definers at the end of the course: PLANTS (7), ANIMALS (5), LIFE (5), STUDY (3), SCIENCE (3), HUMANS (3), ECOLOGY (2), and FOOD (2).

Since both study groups had the same teacher and curriculum content, a similar structure and meaning was expected. However, the use of concept maps appeared to impose a different way to organize information, as shown in Figure 5. The main difference in terms of meaning was that, for the experimental group, the concept of energy as related to animals and plants was assimilated by the students to meaning formation. This concept was implicit in the control group (Figure 4, top left in the control concept net) at the beginning of the course, but it was not integrated in the general net after learning.

Finally, it must be noted that schemata-related concepts to be compared in a semantic priming study at the end of the course, these concepts were selected from computer simulated schemata behavior (10 word pairs). Specifically, the matrix of connectivity among concepts used to build GEPHI net graphs at the end of the course was also used to simulate emergent schemata behavior in a constraint satisfaction neural net, as proposed by Rumelhart, Smolensky, McClelland, \& Hinton (1986). Figure 7 shows the EVCOG interface that allows a researcher to do this. Here, highest common definers in a natural semantic can be clamped (maintained activation) in combination with other concepts to identify which concepts are central to schemata emergent behavior.

Table 2 shows stimuli used in the semantic priming study. Here, associative and non-related word pairs were selected by using word frequency book (Carroll, Davies, \& Richman, 1971) and word length controls were considered.

Notice that computer simulations of schemata behavior can produce a wider set of schemata related concepts.

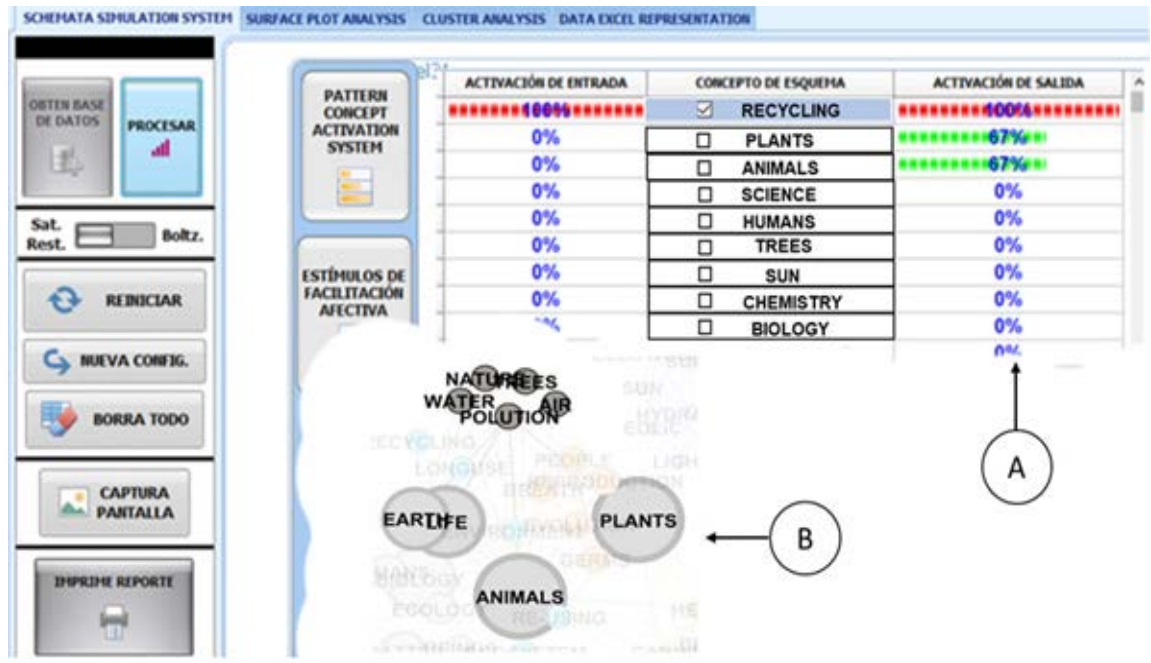

Figure 7. A pattern concept activation output (A) after clamping (maintained activation) RECYCLING. This activation pattern relates to a pollution schema (B) that provides pollution schemata-related word pairs to be used in a semantic priming study. 
Table 2. Stimuli used in the current semantic priming study.

\begin{tabular}{cccccc}
\hline \multicolumn{2}{c}{ ASSOCIATIVE } & \multicolumn{2}{c}{ SCHEMATA } & \multicolumn{2}{c}{ NON-RELATED } \\
\hline Prime & Target & Prime & Target & Prime & Target \\
\hline Bee & Bite & Nature & Recycling & Trigonometry & Spin \\
Airplane & Pilot & Plants & Scientist & Soldier & Guitar \\
Dentist & Tooth & Animals & Energy & Alcoholism & Materials \\
Day & Night & Life & Pollution & Wine & Idea \\
Globe & Hand & Ecosystem & Matter & Universe & Nervous \\
Onion & Tears & Ecology & Science & Carbon & Presidency \\
Cheese & Mouse & Humans & Chain & Regulation & Syncretism \\
Web & Spider & Evolution & Water & Celebration & Language \\
Tennis & Ball & Aliments & Herbivorous & Frog & Universe \\
Cacke & Birthday & Chemistry & Carnivorous & Breast & Tree \\
\hline
\end{tabular}

\section{Discussion}

The aim of this study was to explore how concept mapping affects conceptual change due to learning. Current results support the idea that a cognitive constructive/chronometric approach to learning assessment might reveal not only if concept mapping of biology course contents is effective as a learning tool, but also whether it empowers a teacher with the capacity for discerning the way concept mapping imposes knowledge organization on the acquired conceptual changes.

Due to the concept mapping capacity to visually display conceptual changes, formative learning reports on what is learned are facilitated. For instance, note from Figure 6 that relevant concepts like ECOSYSTEM and ECOLOGY emerged within the newly acquired knowledge schema after the course completion (the same observation applies to the control group). However, while for the experimental the ecosystem concept was related to concepts such as REUSABILITY, RECYCLING, LONG USE, etc., the control group members related both concepts only to animals and plants. When the teacher was questioned about this difference, he argued that concept maps induced experimental group members to consider ecosystem as a broader category. This was an intended learning goal and concept mapping might have helped in attaining it.

In any case, this kind of learning assessment of differences in meaning formation due to conceptual change are neither the goal nor at the reach of summative learning.

Finally, note that chronometric evaluation shown in Figure 2 differentiates the experimental group from the control. First, schemata priming effects are obtained only for the experimental group. Second, the experimental group is faster that the control through all experimental conditions (Figure 1 and Figure 2). The reason for this last difference is unknown. There is no way to attach this result to concept map using from the current study results. 


\section{Conclusion}

More research is needed to determine specific effects of using concept maps on acquiring mental representations of course content knowledge. For instance, selected concepts from schemata simulations can be identified in a concept map. Next time the same course is provided to a new student, these schemata-related concepts can be emphasized as relevant to map construction. The idea is to check if these kinds of manipulations affect schemata priming at the end of course.

\section{Conflicts of Interest}

The authors declare no conflicts of interest regarding the publication of this paper.

\section{References}

Allen, D., \& Tammer, K. (2003). Approaches to Cell Biology Teaching: Mapping the Journey. Concept Maps as Signposts of Developing Knowledge Structures Cell. Biology Education, 2, 133-136. https://doi.org/10.1187/cbe.03-07-0033

Arieli-Attali, M. (2013). Formative Assessment with Cognition in Mind: The Cognitively Based Assessment of, for and as Learning (CBALTM) Research Initiative at Educational Testing Service. Proceedings of the 39th annual Conference on Educational Assessment 2.0: Technology in Educational Assessment.

Ausubel, D. P., Novak, J. D., \& Hanesian, H. (1986). Educational Psychology: A Cognitive View (2nd ed.). New York: Werbel and Peck (Reprinted).

Becker, S., Moscovitch, M., Behrman, M., \& Joordens, S. (1997). Long-Term Semantic Priming: A Computational Account and Empirical Evidence. Journal of Experimental Psychology: Learning, Memory and Cognition, 23, 1059-1082. https://doi.org/10.1037/0278-7393.23.5.1059

Bersano-Méndez, N. I., Schaefer, S. E., \& Bustos-Jimenez, J. (2012). Metrics and Models for Social Networks. In A. Abraham \& A. E. Hassanien (Eds.), Computational Social Networks: Tools, Perspectives and Applications (pp. 115-142). London: Springer Verlag. https://doi.org/10.1007/978-1-4471-4048-1

Bunting, C., Coll, R. K., \& Campbell, A. (2006). Student Views of Concept Mapping Use in Introductory Tertiary Biology Classes. International Journal of Science and Mathematics Education, 4, 641-668. https://doi.org/10.1007/s10763-005-9014-7

Carroll J. B., Davies, P., \& Richman, B. (1971). Word Frequency Book. New York: American Heritage Publishing Co., Inc.

Clariana, R. B. (2010a). Multi-Decision Approaches for Eliciting Knowledge Structures. In D. Ifenthaler, P. Pirnay-Dummer, \& N. M. Seel (Eds.), Computer-Based Diagnostics and Systematic Analysis of Knowledge (pp. 41-60). New York, NY: Springer Verlag. https://doi.org/10.1007/978-1-4419-5662-0_4

Clariana, R. B. (2010b). Deriving Individual and Group Knowledge Structure from Network Diagrams and From Essays. In D. Ifenthaler, P. Pirnay-Dummer, \& N. M. Seel (Eds.), Computer-Based Diagnostics and Systematic Analysis of Knowledge (pp. 117-130). New York, NY: Springer Verlag. https://doi.org/10.1007/978-1-4419-5662-0_7

Conway, M. A., Cohen, G., \& Stanhope, N. (1991). On the Very Long-Term Retention of 
Knowledge Acquired Through Formal Education: Twelve Years of Cognitive Psychology. Journal of Experimental Psychology: General, 120, 395-409.

https://doi.org/10.1037/0096-3445.120.4.395

Conway, M. A., Cohen, G., \& Stanhope, N. (1992). Very Long-Term Memory for Knowledge Acquired at School and University. Applied Cognitive Psychology, 6, 467-482. https://doi.org/10.1002/acp.2350060603

Daley, B. J., Cañas, A. J., \& Stark-Schweitzer, T. (2007). CmapTools: Integrating Teaching, Learning, and Evaluation in Online Courses. New Directions for Adult and Continuing Education, 113, 37-47. https://doi.org/10.1002/ace.245

Dervensteva, N., \& Safayeni, F. (2004). Experiments on the Effects of Map Structure and Concept Quantification during Concept Map Construction. In: A. J. Cañas, J. D. Novak, \& F. M. González (Eds), Concept Maps: Theory, Methodology, Technology. Proc. of the First Int. Conference on Concept Mapping. Pamplona, España.

Farrand, P., Hussain, F., \& Hennessy, E. (2002). The Efficacy of the "Mind Map" Study Technique. Medical Education, 36, 426-431. https://doi.org/10.1046/j.1365-2923.2002.01205.x

Figueroa, J. G., Gonzales, G. E., \& Solis, V. M. (1975). An Approach to the Problem of Meaning: Semantic Networks. Journal of Psycholinguistic Research, 5, 107-115. https://doi.org/10.1007/BF01067252

GEPHI (2017). Force Atlas Method. http://gephi.github.io

Gonzalez, C. J., Lopez, E. O., \& Morales, G. E. (2013). Evaluating Moral Schemata Learning. International Journal of Advances in Psychology, 2, 130-136. http://www.seipub.org/ijap/AllIssues.aspx?PublicationID=282

Holley, C. D., \& Danserau, D. F. (1984). Networking: The Technique and the Empirical Evidence. In C. D. Holley, \& D. F. Danserau (Eds.), Spatial Learning Strategies: Techniques, Applications and Related Issues (pp. 81-108). New York: Academic Press. https://doi.org/10.1016/B978-0-12-352620-5.50010-2

Hyerle, D. (2009). Visual Tools for Transforming Information into Knowledge (2nd ed.). Thousand Oaks, CA: Corwing Press.

Jonassen, D. H., Beisner, K., \& Yacci, M. (1993). Structural Knowledge: Techniques for Representing, Conveying and Acquiring Structural Knowledge. Hillsdale, NJ: LEA.

Jonassen, D., \& Marra, R. M. (1994) Concept Mapping and Other Formalisms as Mindtools for Representing Knowledge. ALT-J, 2, 50-56. https://doi.org/10.3402/rlt.v2i1.9573

Karpicke, J. D., \& Blunt, J. R. (2011). Retrieval Practice Produces More Learning than Elaborative Studying with Concept Mapping. Science, 331, 772-775. https://doi.org/10.1126/science.1199327

Kinchin, M. I. (2015). Concept Mapping in Biology. Journal of Biological Education, 34, 61-68. https://doi.org/10.1080/00219266.2000.9655687

Lalor, S. B., \& Rainford, M. (2014). The Effects of Using Concept Mapping for Improving Advanced Level Biology Students' Lower and Higher-Order Cognitive Skills. International Journal of Science Education, 36, 839-864. https://doi.org/10.1080/09500693.2013.829255

Liu, S. H., \& Lee, G. G. (2013). Using a Concept Map Knowledge Management System to Enhance the Learning of Biology. Computers \& Education, 68, 105-116. https://doi.org/10.1016/j.compedu.2013.05.007

Martin, L. G., Martin, F. A., \& Southworth, E. (2015). A Critical Review of Concept Mapping Research Literature: Informing Teaching and Learning Practices in GED Prepara- 
tion Programs. New Horizons in Adult Education \& Human Resource Development, 27, 27-45. https://doi.org/10.1002/nha3.20109

McAleese, R. (1999). Concept Mapping a Critical Review. Innovations in Education \& Training International, 36, 351-360. https://doi.org/10.1080/1355800990360411

Mcnamara, T. P. (2005). Semantic Priming: Perspectives from Memory and Word Recognition (Essays in Cognitive Psychology). New York: Psychology Press, Taylor \& Francis Group. https://doi.org/10.4324/9780203338001

Morales, M. G. E., \& Lopez, R. E. O. (2016). Cognitive Responsive e-Assessment of Constructive e-Learning. Journal of e-Learning and Knowledge Society, 12, 10-19.

Morales, M. G. E., \& Santos, M. G. (2015). Alternative Empirical Directions to Evaluate Schemata Organization and Meaning. Advances in Social Sciences Research Journal, 2, 51-58. https://doi.org/10.14738/assrj.29.1412

Morales, M. G. E., Lopez, R. E. O., Castro, C., Villarreal, T., \& Gonzales, T. C. J. (2017). Cognitive Analysis of Meaning and Acquired Mental Representations as an Alternative Measurement Method Technique to Innovate e-Assessment. European Journal of Educational Research, 6, 455-464. https://doi.org/10.12973/eu-jer.6.4.455

Nesbit, J. C., \& Adesope, O. O. (2006). Learning with Concept and Knowledge Maps: A Meta-Analysis. Review of Educational Research, 76, 413-448. https://doi.org/10.3102/00346543076003413

Nesbit, J. C., \& Adesope, O. O. (2013). Concept Maps for Learning. In Learning through Visual Displays (pp. 303-328). Charlotte, NC: Information Age Publishing.

Rumelhart, D. E., Smolensky, P., McClelland, J. L., \& Hinton, G. E. (1986). Schemata and Sequential thought Processes. In J. L. McClelland, D. E. Rumelhart, \& The PDP Research Group (Eds.), Parallel Distributed Processing: Explorations in the Microstructure of Cognition, Vol. 2: Psychological and Biological Models (pp. 6-57). Cambridge, MA: MIT Press.

Schroeder, N. L., Nesbit, J. C, Anguiano, C. J., \& Adesope, O. O. (2017). Studying and Constructing Concept Maps: A Meta-Analysis. Educational Psychology Review, 30, 431-455. https://doi.org/10.1007/s10648-017-9403-9

Torres, F., \& Garza, S. E. (2014). Similarity for Natural Semantic Networks. In A. M. Traina, C. Traina Jr., \& R. L. F. Cordeiro (Eds.), 7th International Conference on Similarity Search and Applications (pp. 29-31). Los Cabos: SISAP.

https://doi.org/10.1007/978-3-319-11988-5_18

Wallace, J. D. (1990). The Concept Map as a Research Tool: Exploring Conceptual Change in Biology. Journal of Research in Science Teaching, 27, 1033-1052. https://doi.org/10.1002/tea.3660271010

Wang, C. X., \& Dwyer, F. M. (2006). Instructional Effects of Three Concept Mapping Strategies in Facilitating Student Achievement. International Journal of Instructional Media, 33, 135-151. 